\title{
ENTERPRISE RESOURCE PLANNING TODAY
}

\author{
J. Sunshine Vanover, Texas A\&M University - Kingsville, ksjsv00@tamuk.edu \\ Jack D. Shorter, Texas A\&M University - Kingsville, jackshorter@hotmail.com
}

\begin{abstract}
Enterprise Resources Planning (ERP) is a software solution that began in the 1960s when IBM and J.I. Case partnered to integrate their manufacturing processes using Material Requirements Planning (MRP). ERP application software is presently distributed and maintained by SAP, Oracle, and Microsoft. ERP combines related aspects of business management such as, Finance, Supply Chain Management (SCM), Computer Integrated Manufacturing (CIM), Customer Relationship Management (CRM), Scheduling, Inventory, and Project Management into one software platform that allows businesses to communicate via a single database. The biggest single issue in ERP is the failure of a successful implementation.
\end{abstract}

Keywords: ERP, Enterprise Resource Planning, MRP, SCM, CIM

\section{INTRODUCTION}

Enterprise Resource Planning (ERP) is no longer a fresh, new topic kicked around only by large multimillion dollar corporations. ERP became popular in the early to mid 1990s. Large corporations began to spend millions of dollars on Information Technology (IT) in the race for competitive advantage. ERP was primarily utilized by manufacturers to consolidate the data available from the customer service representatives, inventory, purchasing, production, and finance departments. This integration would help control repetition and lessen the amount of variance throughout the system leaving time for more profitable activities by employees.

Although Enterprise Resource Planning is the topic of this research, related management systems are mentioned, such as Customer Relationship Management (CRM), Material Requirements Planning (MRP), and Supply Chain Management (SCM); only because it would be a disservice to the reader to not fully grasp the potential, combined effect of them all. Nevertheless, ERP is the focus of this report and will serve as its basis.

\section{HISTORY}

Enterprise Resource Planning (ERP) truly began as an extension of Material Requirements Planning (MRP) in the 1960s when IBM and J. I. Case, a tractor manufacturer in Racine, Wisconsin, partnered to improve inventory and planning methods for Case [11]. MRP, regardless of product(s) being manufactured, has three objectives: (1) ensure adequate supplies of raw material are available for production and subsequent delivery to customers, (2) keep inventories low but still able to meet all production needs, and (3) plan purchasing, manufacturing, and delivery activities. MRP calculates backwards from the delivery date to determine the ship date and production date. It also estimates the raw materials necessary and the time required to make each part. In short, the MRP software answers these questions: What items are required, how many are required and when are they required [9].

By the turn of the century, at least a dozen large ERP software vendors had emerged. IBM had stiff competition as countries across the globe were taking advantage of this new inter-enterprise software. It was now possible to interweave all departments of a corporation with the use of one software package and a lot of grit [11].

\section{SOFTWARE VENDORS}

In 1972, five engineers in Germany started a software company called Systemanalyse und Programmentwicklung (SAP). Their intent was to create a software line that would become the backbone of all inter-business related communication solutions. Meanwhile, MRP was becoming increasingly popular among the manufacturing and production industry. In 1977, Jack Thompson, Dan Gregory, and Ed McVaney founded JD Edwards. In the same year, Larry Ellison started Oracle Corporation. During the next decade, Oracle became the first to market a commercial SQL relational database management system, edging out IBM by just two weeks. JD Edwards focused on IBM's System/38 but led off with IBM AS/400, a follow up of System/38. In 1987, Peoplesoft was founded by Dave Duffield and Ken Morris. Their specialty was 
human resource management, and by the end of the decade Peoplesoft had $50 \%$ of the human resources software market share [11].

The impending Millennium had businesses across the world scrambling to get their software up to speed so that in the event of undeterminable disaster, they would not lose their information and data [12]. Microsoft is clearly the leader in computer software. Still, it has been acquiring smaller companies for the past several years while planning to redistribute a software package that is a composite of all business management solutions. This package had tentatively been called "Project Green." In September 2005, Microsoft made an announcement that the new ERP brand will be named Microsoft Dynamics. It will replace the current Microsoft Business Solutions line and will be deeply integrated with Microsoft Office. Microsoft Dynamics will encompass finance, manufacturing, supply-chain management, customer relationship management (CRM), project management, service and more. The current versions of Microsoft Axapta, Great Plains, Navision, and Solomon will remain on the market and will gradually be phased out as Microsoft Dynamics is fully released in 2008. Microsoft CRM is the only product line that will be sold as both a packaged, and as a stand alone product [7].

SAP is relatively obscure to most people; however, it is the fourth largest software company, behind IBM, Microsoft, and Oracle. Supporting large and small corporations, governmental agencies, and educational institutions across the world is what has positioned this software giant at the top of this genre. Currently, SAP's central product is SAP R/3, a three tier framework of database, application server and client. SAP Business One combines areas such as administration, financial, sales and accounting, purchasing, warehouse management, final assembly, controlling, and reporting to be a comprehensive solution to resource management [10].

Oracle is the next largest software vendor in the ERP market today. It began thirty years ago as Larry Ellison happened upon a "working prototype for a relational database." He realized that no one had commercialized the technology and believed the business potential was colossal. Ellison and cofounders, Bob Miner and Ed Oates had stumbled upon an unused technology that would change business and information management [8].

Oracle's goal is to provide a single platform from which an organization can retrieve, collate, and share all business data. Oracle has the broadest range of software available to customers. Database software, application software, and intricate information architecture are available as a broad stroke or industry specific software [8]. In September 2003 Oracle merged with JD Edwards to strengthen its hold on the ERP market. More recently, in June 2005 Oracle merged with Peoplesoft to solidify an even larger share of this market. JD Edwards had a handle on accounting software, where Peoplesoft had its area of expertise in the human resources management area. Oracle's goal is to provide better information at lower costs to customers. They believe that by expanding their platform of services offered to customers they can manage all systems better as a whole and add value to all. Today, Oracle is rated number one in human resource management, supplychain management, and customer relationship management [8].

Lately, there has been a trend to deliver ERP to the small to mid-sized market. Microsoft, SAP, and Oracle are all in a dead heat to mine this vastly unclaimed territory. This technology has always been available to smaller markets, but not as easily adapted to their unique requirements. Each company mentions scalability as a factor in considering which software giant to choose. Predominantly through mergers, these companies have acquired the base necessary to offer complete packages to customers. Each seem to commit their products to greater manageability, reduction in duplication, and automated business flows [1].

\section{IMPLEMENTATION}

Implementation is not an easy task. It often reshuffles the responsibilities of some of the departments. In an implemented ERP system, the initial customer contact is no longer an order taker. They must now be knowledgeable of all departments and know all the right questions to ask to avoid delay. Once the order is entered, all departments have access to the information and the computer immediately begins forecasting adjustments to raw material orders, scheduling, delivery, shipping, billing, and other processes. At any time the information may be accessed by any department and the status of the order is known immediately. Any changes made to the order are made within seconds throughout the company [6].

As you can see, the value of this software is immeasurable. The biggest hurdle is the implementation phase. ERP is a replication of how businesses already conduct business and it may take up to several years to get a company fully aligned 
with a new software platform. Companies have the option of setting up one or several modules or diving in to realign the entire system. A company may have the option of customizing the vendor's generic platform. However, ERP software venders encourage companies to adapt to the available, out-of-box platforms to reduce current and future hiccups when upgrading. In every software upgrade or realignment there seem to be obstacles to overcome. Companies must not let the difficulty of the implementation phase cause them to delay changes. It is necessary to look long-term and see the benefits to the company and the bottom line [6].

\section{COST OF IMPLEMENTATION}

The cost of ERP software ranges from 1,500 to over 100 million dollars, depending on the size of the company, number of installations, and degree of integration. Another variable in the cost of implementation is the existing hardware and network architecture of the purchasing company [12]. Costs will be less for those companies that do not fully integrate their system but the potential rewards will not be as great. It is difficult to quote a complete installation and upgrade figure as hundreds of variables are involved. When discussing costs of implementing or upgrading new software, one cannot ignore the residual costs, such as integration testing, consulting fees, training, and maintenance. These costs will exceed the cost of the software by as much as a factor of ten. Again, one must focus on the end result [9].

Studies show that out of 63 companies, it took an average of 31 months from the initial implementation to realize any benefits. The average savings per year was \$1.6 million dollars. Also, the study noted that 80 percent of Fortune 500 companies had installed ERP platforms [4].

\section{ADVANTAGES}

In every industry the tendency is to do more with less; more production with fewer man hours and more return with less investment. Given the time and resources necessary to properly implement an ERP program, a company should realize exponential profits and see the end-to-end process require less attention. As mentioned before, Material Requirements Planning (MRP) was the precursor to ERP and thus has been in place for a number of years prior to the integration of the financial, CRM, and other modules. Duplication of input can be reduced to nearly nothing when ERP is in place. Communication within the company is multiplied by the availability of information to all departments involved. Billing can be automated as well as human resource functions that usually require a small army to function. The human factor is limited, which decreases the opportunity for errors. Control is increased and the final output is less variable, making the profit margins more consistent [3].

\section{DISADVANTAGES}

At first, it may seem as though the disadvantages far outnumber the advantages. This is not the case. Implementation is the most difficult step. Also, it is the first and longest step. Implementation is arduous, costly, and nightmarish. The fear is that the conversion does not come easily; usually it won't. It is difficult for outside consultants to come into a company and decide what software is appropriate. Frequently, companies must have employees relearn their tasks based on the system requirements of the new software. Sometimes this requires learning different skills. Invariably, personnel are shuffled around to find the best fit for their skills to the given tasks. These testing periods are difficult for all involved and as a product of human nature, employees naturally reject some of the new technology simply because they do not like change.

It has been noted that a major problem for many companies during this transitional phase is they tend to maintain the employees in their old workstations even though they lack the new necessary skills. Researchers have concluded that it is in the best interest of the company to have the most qualified individuals at those stations. This is a critical period and must not be left to chance [6].

The biggest single issue in ERP today is the failure of a successful implementation. Despite the horror stories of some companies, major ERP gaffes are still taking place. There are many reasons why ERP implementations fail. Some of them are a lack of top management commitment, inadequate requirement definitions, poor ERP package selection, inadequate resources, resistance to change/lack of buy-in, miscalculation of time and effort, a misfit of application software with business processes, unrealistic expectation of benefits and ROI, inadequate training and education, poor project design and management, poor communications, and ill-advised cost cutting. It should be remembered that information systems are part of a company infrastructure, and therefore are strategic to the company's survival and success. It should also be noted that ERP and information systems are there to support business functions and increase productivity, 
not the reverse. Finally, many companies should learn from the successes and failures of others and not attempt to reinvent the wheel of ERP implementation practice [13].

Due to the multitude of things that could go wrong during this initial phase, many companies see a decline in revenue after the first quarter. This is exceedingly common. The entire system may be up and running, but it isn't running very fast because the users of this new system are not up to speed. Virtually every employee is reverting back to their experiences from there past. Many will do better as they go along, but a few will remain in their comfort zone. Studies have indicated that a small amount of the new software is being utilized. Companies should encourage each department to maximize the use of the new software capabilities. While the disadvantages are for the most part front loaded, they can be overcome [5].

\section{SUCCESS STORY}

Dixie Iron Works (DIW) in Alice, Texas, is a great example to illustrate the benefits of an ERP system. DIW produces a line of oil field high-pressure oil plugs. They are well known for fast turnaround and emergency service to their customers. Despite their superior reputation, they were only completing 5 percent of their scheduled jobs on time. Inventories were high, and their profits low. Gerard Danos, then Vice-President of Operations, wrote that he was charged with finding a software system to help them align their manufacturing, scheduling, purchasing, and financial departments [2].

Danos contacted Tamlin Software Development and decided to integrate three independent ERP modules to satisfy the company's software needs. Soon after the software was implemented, they began to see improvements. The software predicted bottlenecks in the system in time for the scheduler to acknowledge them and have the software recalculate a solution. "It suggests optimal overtime, allows alternate routings, minimizes changeover and shows the impact on throughput and delivery dates. With a few clicks of a mouse, we can now schedule our shop in 15 to 30 minutes." DIW has doubled its inventory turns per year since the implementation of the software and has increased its due date performance by 60 percent. They continue to increase sales and increase their profits by 50 percent each year [2].

\section{CONCLUSIONS}

ERP has finally integrated all facets of business into most industries. SAP, Oracle, and Microsoft are the most significant players on the field that is still growing, merger by merger. The most daunting challenge of any ERP program is the implementation phase. This phase can last for up to two to three years for a complete end-to-end installation. The disadvantages come early and last for several years before most advantages are realized. The advantages are many and make the grueling first phase worthwhile.

ERP can take a struggling company and improve the companies' bottom line. It can take a great company to heights it has never dreamed of when calculating profits and customer service. Success stories are becoming more prevalent throughout the Fortune 500 community. This type of software is also having an impact on midsized and small companies, according to the latest research. Current software releases are focusing more on the untapped smaller corporations for the next big push by ERP vendors.

\section{REFERENCES}

1. Cowley, S. (2005 August 15). Apps vendors attack midmarket. CRM and ERP vendors offer deeper integration, customization features. Infoworld, 27(32), 14 -15.

2. Danos, G. (2005). Dixie Iron Works: After installing finite capacity scheduling software, Dixie's scheduler asked for more to do. Retrieved October 17, 2005 from http://www.goldratt.co.uk/succ/dixie.htm

3. Furth, D. (2005). Accounts payable automation pays dividends. The CPA Journal, 75(7), 16.

4. Gattiker, T., \& Goodhue, D. (2005). What happens after ERP implementation: understanding the impact of interdependence and differentiation on plant-level outcomes? MIS Quarterly, 29(3), 559 - 585.

5. Jasperson, J., Carter, P., \& Zmud, R. (2005). A comprehensive conceptualization of postadoptive behaviors associated with information technology enable work systems. MIS Quarterly, 29(3), $525-557$.

6. King, W. (2005). Ensuring ERP implementation success. Information Systems Management, 22(3), $83-84$.

7. Microsoft Corporation. (2005, September 6). Microsoft introduces Microsoft dynamics brand Q\&A: Microsoft corporate VP Tami Reller discusses how the new brand is reflective of "Project Green." Retrieved January 15, 2006, 
from

http://www.microsoft.com/presspass/features/wo ot/sep05/0906Brand.mspx

8. Oracle Corporation. (2006). Oracle. Retrieved February 15, 2006, from http://www.oracle.com/corporate/story.html

9. Robinson, P. (2005). ERP (Enterprise Resource Planning) survival guide - How to live with an MRPII (Manufacturing Resource Planning) or ERP (Enterprise Resource Planning) system and get real business benefits. Retrieved October 18, 2005, from http://www.bpic.co.uk/erp.htm

10. Sap A. G. (2005, October 12). SAP releases 28 new versions of best practices offerings for midsize enterprises. Retrieved October 15, 2005 , from http://www.sap.com/company/Press.exp

11. Sap A. G. (2005, October 7). ERP History. Retrieved October 17, 2005, from http://www.saptech.8m.com/erp_history.htm

12. Snyder, D. (2005). Is it time to spend money on IT again? The CPA Journal, 75(7), 15.

13. White Paper. (2004). The cardinal sins of ERP implementation. Retrieved May 26, 2006, from http://www.rockfordconsulting.com/12sinart.htm 